\title{
EVALUACIÓN DE MARCADORES GENÉTICOS PARA DISCRIMINACIÓN ENTRE HEMBRAS Y HERMAFRODITAS DE PAPAYA (Carica papaya L.) VARIEDAD 'MARADOL'
}

\section{EVALUATION OF GENETIC MARKERS FOR DISCRIMINATION BETWEEN FEMALES AND HERMAPHRODITES OF PAPAYA (Carica papaya L.) CV. 'MARADOL'}

\author{
Violeta Aspeitia-Echegaray, Ma. Alejandra Torres-Tapia, Dulce V. Mendoza-Rodríguez \\ y M. Humberto Reyes-Valdés*
}

\begin{abstract}
Departamento de Fitomejoramiento, Universidad Autónoma Agraria Antonio Narro. Calzada Antonio Narro 1923. 25315, Saltillo, Coah., México. Tel. (844)4110296.

${ }^{\star}$ Autor para correspondencia(MathGenome@gmail.com)
\end{abstract}

\section{RESUMEN}

La papaya (Carica papaya L.) presenta tres tipos sexuales: macho, hembra y hermafrodita, de los cuales solo el último posee valor comercial y calidad de exportación. Con base en su morfología, dichos tipos únicamente pueden ser identificados a partir de la floración. La segregación del sexo en esta especie se explica con un modelo de un locus multialélico, aunque tiene una base molecular más compleja ya que puede intervenir más de un gen. En la papaya 'Maradol' se presentan casi exclusivamente los tipos femenino y hermafrodita, por lo cual en esta variedad se busca solamente la distinción entre ambas formas sexuales. En este trabajo se probaron tres juegos de iniciadores para marcadores SCAR, previamente desarrollados para determinación del sexo en variedades hawaianas. Los tres marcadores se identifican como T1, T12 y W11. A partir de tejido de 17 plantas identificadas como hembras y 23 hermafroditas de papaya 'Maradol', se encontró que los marcadores T12 y W11 fueron específicos en $100 \%$ para plantas hermafroditas, mientras que no se observó amplificación para las plantas hembra. el SCAR T1 amplificó ADN solamente en algunas plantas hermafroditas. Se concluye que los SCAR T12 y W11 pueden ser utilizados como parte de una técnica para identificación temprana del sexo de las plantas de papaya 'Maradol' con fines de plantación comercial, previa validación con otras poblaciones de la misma variedad.

Palabras clave: Caricaceae, sexo, marcadores moleculares, SCAR.

\section{SUMMARY}

Papaya (Carica papaya L.) shows three sexual types: male, female and hermaphrodite, from which only the last one has commercial value and export quality. Morphologically, such types are only distinguishable starting at flowering stage. Sex segregation in this species is explained by a multiallelic locus, even though it is more complex at the molecular level. In 'Maradol' papaya, the female and hermaphrodite types are almost the only present sexual forms, so that the distinction between these two forms is sought. In this work, three sets of SCAR primers, previously developed for Hawaiian varieties, were tested. The three markers are identified as T1, T12 and W11. From tissue of 17 female and 23 hermaphrodite plants, it was found that the markers T12 and W11 showed $100 \%$ specificity for hermaphrodite individuals, with null amplification for female plants. On the other hand, the T1 SCAR primers amplified DNA only in some hermaphrodite plants. It is concluded that T12 and W11 SCAR markers can be used as a part of a technique to identify plant sex in early stages of 'Maradol' papaya for commercial cultivation purpose, after validation with other populations of the same variety.

Index words: Caricaceae, sex, molecular markers, SCAR.

\section{INTRODUCCIÓN}

Se considera que la papaya (Carica papaya L.) cultivada es originaria del sur de México y Costa Rica (Gil y Miranda, 2008). Es una planta herbácea alta, de crecimiento rápido y de vida corta (Alonso et al., 2009); sus hojas son de porte grande y alcanza una altura de $10 \mathrm{~m}$ y una edad de 15 a 30 años. El tamaño del fruto varía entre $100 \mathrm{~g}$ y $10 \mathrm{~kg}$. Su forma va de redonda-ovalada hasta oblonga (Augstburger et al., 2000). México es uno de los principales exportadores de papaya, ya que envía a los mercados internacionales alrededor de $30 \%$ de la producción nacional (SIAP, 2013).

La papaya es trioica o poligámica, con flores masculinas, femeninas y hermafroditas en plantas separadas (Urasaki et al., 2012). Las plantas con flores hermafroditas producen frutos con las mejores características comerciales: forma alargada y piel gruesa, lo cual les permite resistir a los daños mecánicos en postcosecha, y una cavidad interna pequeña, es decir, una mayor relación pulpa/semilla; sin embargo, el sexo de estas plantas sólo puede ser determinado hasta que los individuos llegan a la floración, lo cual ocurre de dos a tres meses después de la siembra.

La segregación sexual en la papaya se explica con un modelo de un locus con tres alelos: $M$, macho; $M^{h \text {. }}$ hermafrodita; y $m$ hembra, con los alelos $M$ y $M^{h}$ dominantes sobre $m$. Las hembras $(\mathrm{mm})$ son homocigóticas recesivas. Los machos $(M m)$ y hermafroditas $\left(M^{h} m\right)$ son heterocigóticos. Las plantas hermafroditas típicamente producen $25 \%$ de semillas no viables en sus frutos, porque todas las combinaciones de dos alelos dominantes $\left(M M, M M^{h}\right.$ y $\left.M^{h} M\right)$ son embriogénicamente letales. Aunque este modelo explica de forma satisfactoria las frecuencias de segregación típicas en papaya, la determinación del sexo es más compleja, y se ha 
revelado la presencia de un par de cromosomas sexuales primitivos (Urasaki et al., 2012).

La variedad 'Maradol' fue obtenida a partir de germoplasma recolectado en la región central y oriental de Cuba. Ha alcanzado gran difusión en México, se extiende por muchos países tropicales y constituye una de las tres variedades de papaya más comercializadas en el mundo (Rodríguez, 2008). 'Maradol' es la más conocida entre las variedades de fruto grande y tiene el primer lugar en importación en los Estados Unidos de América, seguida de las variedades 'Solo' y 'Tainung' (Evans et al., 2012).

En la papaya 'Maradol' persisten casi exclusivamente las formas femenina y hermafrodita, mientras que los machos son prácticamente ausentes. Para obtener una plantación con individuos hermafroditas, el productor de papaya 'Maradol' debe sembrar de tres a cuatro plantas por punto de siembra y eliminar al momento de la floración los fenotipos no deseados. Esta práctica resulta en un aumento de los costos de producción como consecuencia del mayor número de plántulas sembradas y su mantenimiento hasta el momento de ser removidas (Saalau-Rojas et al., 2009). Si se pudiera discriminar entre hembras y hermaforditas a las plántulas de papaya 'Maradol', se ahorrarían recursos como suelo, fertilizantes y agua, además de que la producción sería más amigable con el ambiente.

Se han desarrollado marcadores moleculares capaces de discriminar sexo en algunas variedades de papaya como 'Catira,' 'ILS 647' e 'ILS 649' (Chaves-Bedoya et al., 2009), aunque a la fecha no se tienen reportes de una técnica probada en 'Maradol'. Sin embargo, Sex1, la región determinante del sexo en papaya dispone de tres productos de marcadores de tipo RAPD clonados y parcialmente secuenciados (Deputy et al., 2002).

Para el sexado de plantas de papaya se han utilizado marcadores SCAR (región amplificada con secuencia caracterizada). Este tipo de marcador consiste en un fragmento de ADN genómico identificado con amplificación vía reacción en cadena de la polimerasa (PCR) con un par de iniciadores específicos. Una de sus ventajas sobre los marcadores RAPD es que detectan un locus específico (Semagn et al., 2006).

Deputy et al. (2002) desarrollaron los marcadores SCAR denominados T1, T12 y W11, para los que dichos autores reportan que las combinaciones T12 y W11 amplificaron $\mathrm{ADN}$ en plantas hermafroditas y masculinas, raramente en las hembras de las variedades hawaianas de papaya, mientras que T1 amplificó en los tres tipos sexuales de plantas. Por otra parte, Sánchez-Betancourt y Núñez (2008) trabajaron con 24 plantas de papaya de cultivares de la región de
Mosquera en Cundinamarca, Colombia, con identificación sexual previa, y encontraron que el SCAR W11 fue específico para machos y hermafroditas, con ausencia de bandas en las hembras. En un trabajo más amplio, Saalau-Rojas et al. (2009) con el híbrido 'Pococí de Costa Rica', encontraron especificidad entre la amplificación con W11 y la condición de hermafrodita, con $98 \%$ de concordancia en una muestra de 360 plantas.

La presente investigación se realizó con el fin de probar los marcadores SCAR desarrollados por Deputy et al. (2002), en cuanto a su capacidad para distinguir entre hembras y hermafroditas en papaya 'Maradol'.

\section{MATERIALES Y MÉTODOS}

El material vegetal fue recolectado en el año 2011, de un campo de cultivo comercial de papaya 'Maradol' destinada a la exportación en el rancho Amial, Municipio de Tecomán, Colima, localizado en las coordenadas $18^{\circ} 53^{\prime} 21^{\prime \prime} \mathrm{N}$ y $103^{\circ} 55^{\prime} 25^{\prime \prime} \mathrm{O}$, con una altitud de $25 \mathrm{~m}$. Se recolectaron hojas jóvenes de 40 plantas de $280 \mathrm{~d}$ de edad. El número de muestras por sexo fue variable, de acuerdo con el material disponible en campo en el momento de la recolección: 17 plantas hembras y 23 hermafroditas plenamente identificadas.

El ADN fue extraído de hojas jóvenes deshidratadas, con base en el método Doyle y Doyle (1990). Para la PCR se utilizaron tres juegos de iniciadores reportados por Deputy et al. (2002) (Cuadro 1). La reacción de PCR fue llevada a cabo en volúmenes de $20 \mu \mathrm{L}$ que contenían $4 \mu \mathrm{L}$ de $\mathrm{ADN}$ a una concentración de $100 \mathrm{ng} \mu \mathrm{L}^{-1}, 4 \mu \mathrm{L}$ de Taq- $\& \mathrm{GO}$ (Mastermix $5 \mathrm{xC}, \mathrm{MP} \circledast$ ), $7.6 \mu \mathrm{L}$ de agua, $2.2 \mu \mathrm{L}$ de iniciador $\mathrm{R} y$ $2.2 \mu \mathrm{L}$ de iniciador $\mathrm{F}$, ambos a una concentración de $2 \mu \mathrm{M}$. La optimización de las temperaturas de la reacción se llevó a cabo en un termociclador Mini Cycler ${ }^{\mathrm{TM}}$ (MJ Research, Inc).

El programa consistió de una temperatura inicial de desnaturalización de $95^{\circ} \mathrm{C}$ por 5 min y 25 ciclos con un perfil térmico para cada ciclo de $95^{\circ} \mathrm{C}$ por $60 \mathrm{~s}, 60.1^{\circ} \mathrm{C}$ por 60 s y $72{ }^{\circ} \mathrm{C}$ por $60 \mathrm{~s}$; luego de esto, una extensión final a 72 ${ }^{\circ} \mathrm{C}$ por $7 \mathrm{~min}$. Los productos de la PCR fueron separados mediante electroforesis en gel de agarosa a $1 \%$, teñidos con $8 \mu \mathrm{L}$ de GelRed (Nucleic Acid Gel Stain, 10,000X $0.5 \mathrm{ml}$, Biotium $\left.{ }^{\circledR}\right)$ y las bandas fueron visualizadas en un transiluminador (Transilluminator UVP®).

Los resultados de amplificación con los diferentes juegos de iniciadores en hembras y hermafroditas fueron analizados con la prueba exacta de Fisher para probar la asociación entre marcadores y sexos, en el lenguaje y ambiente estadístico R (R Development Core Team, 2013). La prueba 
exacta de Fisher es utilizada para asociación en tablas de contingencia, donde el valor de $p$ para la significancia en el rechazo de la hipótesis nula, se calcula en forma exacta a través de la distribución hipergeométrica, en lugar de las aproximaciones utilizadas en las pruebas clásicas de chi cuadrada (Logan, 2011).

\section{RESULTADOS Y DISCUSIÓN}

En el Cuadro 2 se muestran los resultados obtenidos con los tres iniciadores utilzados, en cuanto a su efecto en la amplificación de ADN. Para el caso del iniciador T1 los resultados fueron inconsistentes, ya que no se observó amplificación en plantas femeninas y la hubo en 18 de las 23 plantas hermafroditas. Con el iniciador T12 se observó amplificación en todas las plantas hermafroditas pero en ninguna femenina; lo mismo sucedió con el iniciador W11, que presentó $100 \%$ de amplificación en plantas hermafroditas y nula en plantas femeninas. En las Figuras 1 y 2 se observa la amplificación específica para hermafroditas con los iniciadores T12 y W11, respectivamente, y la amplificación de T1 en una planta hermafrodita. Los marcadores T12 y W11 produjeron en las plantas hermafroditas fragmentos de aproximadamente $800 \mathrm{pb}$. Cuando el marcador T1 generó productos de PCR en plantas hermafroditas, los fragmentos fueron de aproximadamente $1300 \mathrm{pb}$.

Adicionalmente, los iniciadores T12 y W11 amplificaron fragmentos en un compuesto de ADN de cinco plantas hermafroditas, mientras que no lo hicieron en un compuesto de ADN de cinco plantas hembra (Figura 3). Los tamaños aproximados de $800 \mathrm{pb}$ para los fragmentos producidos por T12 y W11, y de $1300 \mathrm{pb}$ para T1 coinciden con los reportados por Deputy et al. (2002).

La prueba exacta de Fisher indicó una asociación altamente significativa de los sexos femenino y hermafrodita con los marcadores T12 y W11 $\left(\mathrm{P}=1.27 \times 10^{-11}\right)$. La magnitud extremadamente pequeña de los valores de significancia (P), indica el alto soporte estadístico que tuvo la asociación entre estos marcadores y el sexo en papaya 'Maradol'. La misma prueba también arrojó un resultado altamente significativo para $\mathrm{T} 1\left(\mathrm{P}=3.25 \times 10^{-7}\right)$; sin embargo, no hubo consistencia total en la amplificación de ADN de plantas hermafroditas y en general las amplificaciones no fueron nítidas.

El comportamiento de los iniciadores de T12 y W11, que amplificaron consistentemente segmentos de ADN en los materiales de papaya hermafrodita, concuerda con lo reportado para variedades de Hawaii (Deputy et al., 2002), Colombia (Sánchez-Betancourt y Núñez, 2008) y Costa Rica (Saalau et al., 2009); por tanto, constituyen una base confiable para el diseño de una metodología rápida que permita la identificación del sexo en plántulas de papaya variedad 'Maradol' a temprana edad. Para el caso de T1, aun cuando Deputy et al. (2002) lo reportan como testigo que amplifica en todas las plantas de papaya, en este trabajo se observaron resultados inconsistentes. En caso de que esta inconsistencia persista en estudios posteriores, se deberá buscar otro marcador que funcione como testigo en pruebas de PCR para indentificación del sexo en esta variedad.

$\begin{aligned} & \text { Cuadro 1. Juegos de iniciadores SCAR desarrollados por Deputy et al. } \\
& \text { (2002) evaluados en papaya 'Maradol'. }\end{aligned}$
\begin{tabular}{lc} 
Clave & Iniciador \\
\hline T1-F & 5'-TGCTCTTGATATGCTCTCTG-3' \\
T1-R & 5'-TACCTTCGCTCACCTCTGCA-3' \\
T12-F & 5'-GGGTGTGTAGGCACTCTCCTT-3' \\
T12-R & 5'-GGGTGTGTAGCATGCATGATA-3' \\
W11-F & 5'-CTGATGCGTGTGTGGCTCTA-3' \\
W11-R & 5'-CTGATGCGTGATCATCTACT-3' \\
\hline
\end{tabular}

Cuadro 2. Resultados de amplificación de ADN con tres juegos de iniciadores para marcadores SCAR en plantas femeninas y hermafroditas de la variedad 'Maradol'.

\begin{tabular}{lcccc}
\hline & \multicolumn{2}{c}{ Femeninas } & \multicolumn{2}{c}{ Hermafroditas } \\
\hline SCAR & Positivo & Negativo & Positivo & Negativo \\
T1 & 0 & 17 & 18 & 5 \\
T12 & 0 & 17 & 23 & 0 \\
W11 & 0 & 17 & 23 & 0 \\
\hline
\end{tabular}




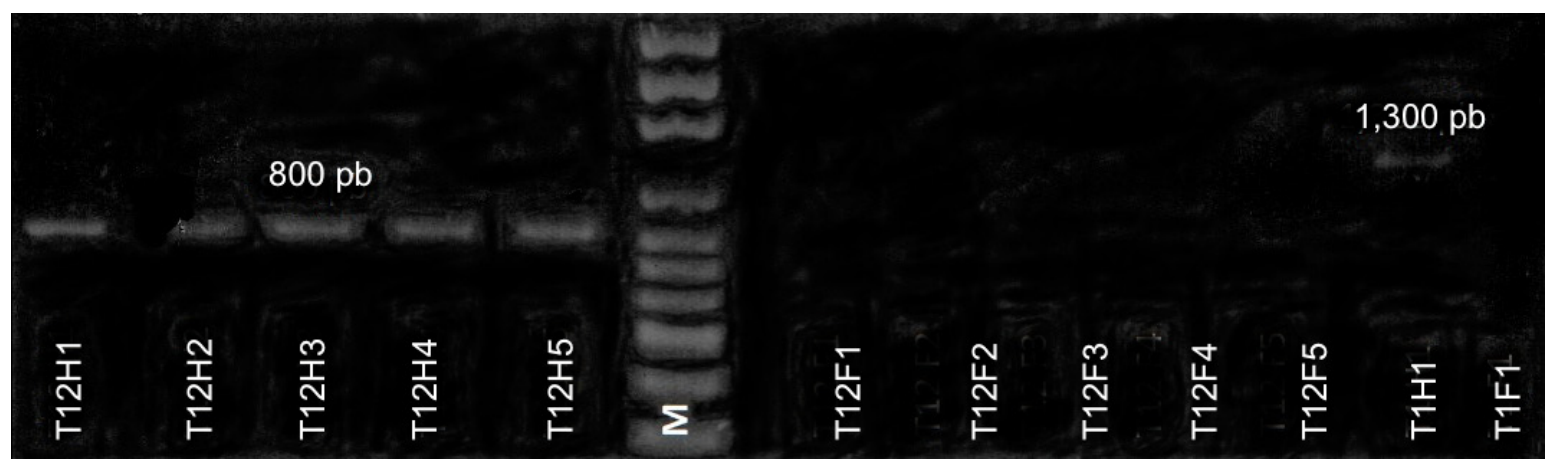

Figura 1. Electroforesis de productos de marcadores SCAR en papaya 'Maradol'. Marcador T12 en plantas hermafroditas $(\mathrm{T} 12 \mathrm{H} 1, \mathrm{~T} 12 \mathrm{H} 2, \mathrm{~T} 13 \mathrm{H} 3, \mathrm{~T} 13 \mathrm{H} 4$ y T13H5), T12 en plantas femeninas (T12F1, T12F2, T13F3, T13F4 y T13F5), T1 en una plantas hermafrodita (T1H1) y T1 en una planta hembra (T1F1). M es el marcador escalera de tamaños.

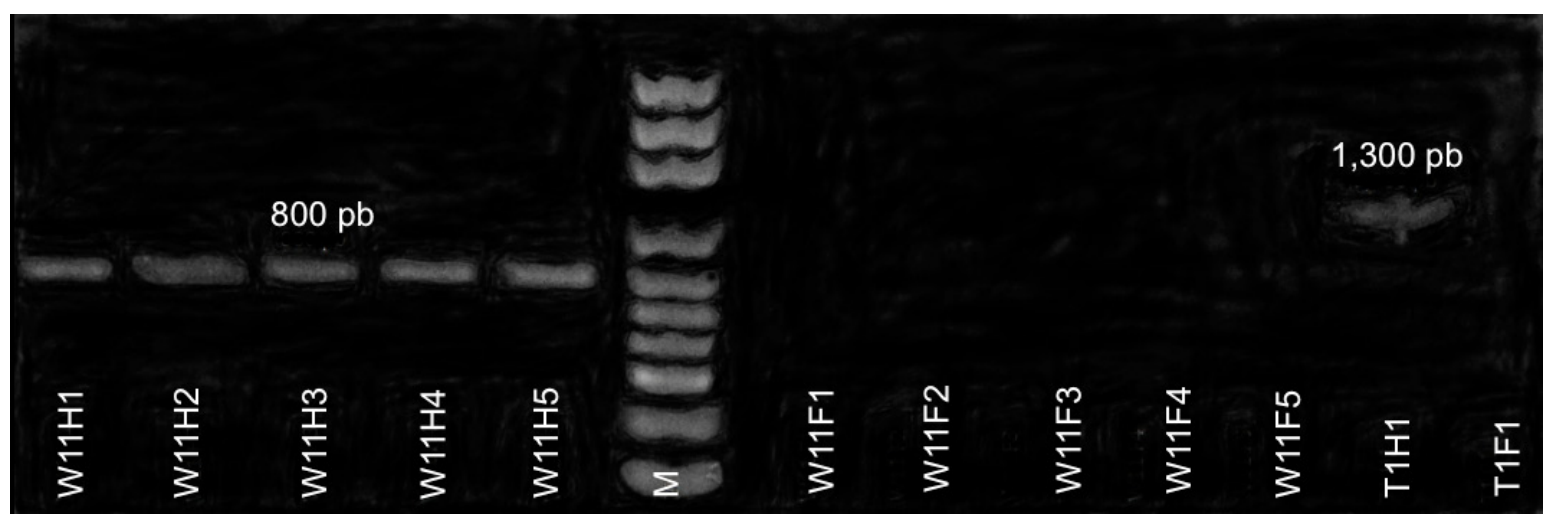

Figura 2. Electroforesis de productos de marcadores SCAR en papaya 'Maradol'. Marcador W11 en plantas hermafroditas $(\mathrm{W} 11 \mathrm{H} 1, \mathrm{~W} 11 \mathrm{H} 2, \mathrm{~W} 11 \mathrm{H} 3, \mathrm{~W} 11 \mathrm{H} 4$ y W11H5), W11 en plantas femeninas (W11F1, W11F2, W11F3, W11F4 y W11F5), T1 en una plantas hermafrodita (T1H1) y T1 en una planta hembra (T1F1). M es el marcador escalera de tamaños.

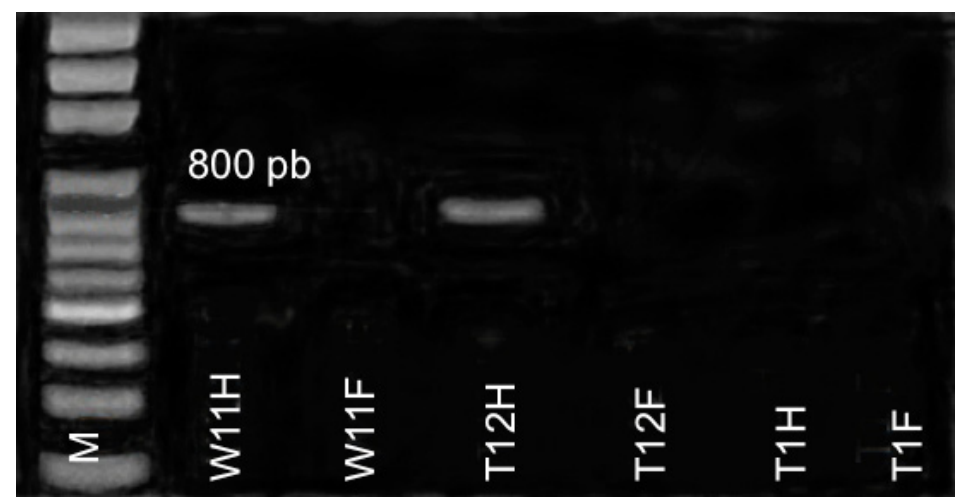

Figura 3. Electroforesis de productos de marcadores SCAR en papaya 'Maradol' en un compuesto de cinco plantas hermafroditas $y$ uno de cinco plantas femeninas. Marcador W11 en plantas hermafroditas $(\mathrm{W} 11 \mathrm{H}), \mathrm{W} 11$ en plantas femeninas (W11F), T12 en plantas hermafroditas (T1H) y T1 en plantas femeninas (T1F). $M$ es el marcador escalera de tamaños. 


\section{CONCLUSIONES}

Dos juegos de iniciadores para marcadores tipo SCAR, T12 y W11, amplificaron bandas de 800 pb con especificidad completa en plantas hermafroditas de la variedad 'Maradol', sin casos de falsos positivos. Por tanto pueden ser usados como base para implementar y validar con más poblaciones un método rápido de identificación del sexo en esta variedad, con fines de selección de plántulas. La consistencia de dichos marcadores para identificar el sexo en papaya para variedades de muy diferentes orígenes, es indicativo de la existencia de una región determinante del sexo en cromosomas bien definidos. Por otro lado, la inconsistencia de los resultados observada para el juego de iniciadores T1, no valida su uso para la identificación del sexo en esta variedad.

\section{BIBLIOGRAFÍA}

Alonso E. M., M. Bautista A., M. Ortiz G., A. Quiroz M., W. Rohde y L. F. Sánchez T. (2009) Caracterización de accesiones de papaya (Carica papaya L.) a través de marcadores AFLP en Cuba. Revista Colombiana de Biotecnología 11:31-39.

Augstburger F., J. Berger, U. Censkowsky, P. Heid, J. Milz and C. Streit (2000) Agricultura Orgánica en el Trópico y Subtrópico: Guías de 18 Cultivos. Papaya. Asociación Naturland. Sin lugar de publicación. 38 p.

Chaves-Bedoya G., M. Pulido, E. Sánchez-Betancourt and V. Núñez (2009) Marcadores RAPD para la identificación del sexo en papaya (Carica papaya L.) en Colombia. Agronomía Colombiana 27:145-149.

Deputy J. C., R. Ming, H. Ma, Z. Liu, M. M M. Fitch, M. Wang, R. Manshardt and J. I. Stiles (2002) Molecular markers for sex deter- mination in papaya (Carica papaya L.). Theoretical and Applied Genetics 106:107-111.

Doyle J. J. and J. L. Doyle (1990) Isolation of plant DNA from fresh tissue. Focus 12:13-15.

Evans E. A., F. H. Ballen and J. H. Crane (2012) An Overview of US Papaya Production, Trade, and Consumption. Publication No. FE914. IFAS Extension. University of Florida. Gainesville, FL, USA. 8 p.

Gil A. I. and D. Miranda (2008) Aspectos anatómicos de la semilla de papaya (Carica papaya L.). Revista Colombiana de Ciencias Hortícolas 2:145-156.

Logan M. (2011) Biostatistical Design and Analysis Using R. A Practical Guide. John Wiley \& Sons, Hoboken, NJ. 546 p.

R Development Core Team (2013) R: A Language and Environment for Statistical Computing. R Foundation for Statistical Computing. Vienna, Austria.

Rodríguez M. A. (2008) De la Ciencia Popular a la Industria: La Variedad Cubana de Papaya "Maradol". SinncO. Observatorio de Ciencia Tecnología e Innovación. Consejo de Ciencia y Tecnología, Estado de Guanajuato, México. 23 p.

Saalau-Rojas E., W. Barrantes-Santamaría, C. L. Loría-Quirós, A. Brenes-Angulo and L. Gómez-Alpízar (2009) Identificación mediante PCR del sexo de la papaya (Carica papaya L.), híbrido "Pococí". Agronomía Mesoamericana 20:311-317.

Sánchez-Betancourt E. and V. M. Núñez Z (2008) Evaluación de marcadores moleculares tipo SCAR para determinar sexo en plantas de papaya (Carica papaya L.). Revista Corpoica - Ciencia y Tecnología Agropecuaria 9:31-36.

Semagn K., A. Bjørnstad and M. N. Ndjiondjop (2006) An overview of molecular marker methods for plants. African Journal of Biotechnology 5:2540-2568.

SIAP, Servicio de Información y Estadística Agroalimentaria y Pesquera (2012) Comercio exterior. SAGARPA. México, D.F. Disponible en http://w6.siap.gob.mx/comercio/con_producto.php. (Octubre 2013).

Urasaki N., K. Tarora, A. Shudo, H. Ueno, M. Tamaki, N. Miyagi, S. Adaniya and H. Matsumura (2012) Digital transcriptome analysis of putative sex-determination genes in papaya (Carica papaya). PLoS ONE 7:e40904. 